\title{
Increase in Warpage Prediction Accuracy for Glass Filled Polyamide Material (PA66) through Integrative Simulation Approach
}

\author{
M. Divekar ${ }^{1}$, V. R. Gaval ${ }^{*}$, A. Wonisch ${ }^{3}$ and G. Jadhav ${ }^{4}$ \\ ${ }^{1}$ Department of General Engineering, Institute of Chemical Technology, Mumbai 400019 India \\ ${ }^{2}$ Faculty of General Engineering Department, Institute of Chemical Technology, Mumbai 400019 India \\ ${ }^{3}$ Team lead-Process analysis, BASF SE, Performance Materials, Ludwigshafen, Rheinland-Pfalz, DE \\ ${ }^{4}$ CAE Engineer, BASF India Ltd, Performance Materials, Mumbai 400019 India
}

\begin{abstract}
The warpage prediction accuracy of the simulation software depends on part geometry, material model and methodology. However, the material model in the existing simulation software's does not consider factors such as nonlinear mechanical properties, temperature dependent behaviour, viscoelastic behaviour and transient description of warpage leading to less accuracy. Using an integrative simulation approach, BASF has developed Ultrasim ${ }^{\circledR}$ tool to overcome limitations in the material model of existing simulation software. In the new material model thermomechanical properties, stress relaxation behaviour and nonlinear mechanical properties were considered and this new material model is added to Ultrasim $^{\circledR}$ tool. The model also considers time dependent descriptions of the warpage starting from packing phase of the moulding process, followed by actual ejection and cooling. In this paper warpage results predicted through new integrative simulation approach and existing simulation approach are compared with actual experimental results for $50 \%$ glass filled polyamide material (Ultramid®A3WG10). The results revealed that warpage values predicted by integrative simulation based Ultrasim ${ }^{\circledR}$ tool are closer to actual experimental results compared to values predicted by existing simulation technologies. Therefore an integrative simulation approach can be used prior to making real parts to reduce manufacturing cost.
\end{abstract}

Keywords: thermomechanical; viscoelastic; warpage; integrative simulation; polyamide

\section{INTRODUCTION}

In injection moulded parts warpage is a common problem leading to dimensionally inaccurate parts which impedes part assembly. Thus, it is required to predict warpage accurately prior to tool development to reduce manufacturing cost, time and money. Presently simulation software's such as moldflow, moldex $3 \mathrm{D}$ etc., are widely used for warpage prediction. Polyamides or Nylon is an important engineering thermoplastic because of its good balance of physical and mechanical properties. Polyamides have high temperature, good oil resistance, and excellent mechanical properties. Hence they are widely used in automotive applications. The glass fibre reinforced polyamides exhibit excellent stiffness and therefore extensively used for replacing metal parts for weight reduction. Warpage in injection moulded component with fibre filled thermoplastics material depends on an orientation of fibres in different directions. The fibre orientation in the moulded part can be controlled by using proper gate size, gate location, injection time, mould and melt temperature. Jian et al. reported optimisation of injection process parameters to reduce warpage in glass fibre reinforced polyamide moulded parts. He concluded that provision of three gate injection method reduces warpage to a great extent due to better fibre orientation (Jian et al., 2015). Akay et al. studied fibre orientation near to the skin and core area of moulded part. He observed occurrence of 
longitudinal fibre orientations near to the skin area and transverse fibre orientations near to the core area. It is also reported that mechanical properties are better in the direction of longitudinal fibre orientations than in transverse fibre orientation direction (Akshay and Barkly, 1991). Divekar et al. have studied warpage prediction of injection moulded parts made of unfilled Poly Butylene Terephthalate (PBT). It is reported that an integrative simulation approach is more accurate than existing simulation approach as far as warpage prediction is concerned. Integrative simulation approach considers thermomechanical, stress relaxation and nonlinear behaviour of the material (Divekar et al., 2020). Izadi et al. carried out experimental and simulation study on the warpage of polyamide- 6 based on thermomechanical behaviour of material. It is reported that generalised Maxwell model can be used effectively to predict time dependent behaviour of PA-6 (Izadi et al., 2019).

Jan-Martin et al. studied micromechanical modelling and prediction of strength for short fibres reinforced polymers. His approach considered non unidirectional fibre distribution occurring during injection moulding process leading to heterogeneous microstructure of polymer composites (Jan-Martin et al., 2012). Kovacs et al. studied effect of loadipolyang and diameter of glass bead on shrinkage and warpage of injection moulded PA6. It is concluded that flow directional shrinkage reduces with the increase in bead loading and bead diameter. However, the deformation factor has increased with increase in bead loading and diameter (Kovacs et al., 2009). Fung (2004) studied fibre orientation distribution for $15 \%$ glass filled Polybutylene Terephthalate (PBT) material. This work focused on fibre orientation distributions near the skin, intermediate and the core area of the moulded part. Folgar et al. developed mathematical model for the prediction of fibre orientation distribution for short fibre composite. He tested mathematical model against experiemental method and observed major defects in the model. The model predicts rapid allignment in transient state than actual. However the model prediction and experimental results shows that prediction are relatable (Folgar and Tucker, 1984). Dani et al. studied effect of strain rate dependent behaviour on glass filled material. He has carried out his research using 10\% glass filled PBT material and blend of PBT(10\%) and thermoplastic polyester elastomer (TPEE). He has also studied effect of strain rate on fracture behaviour. He found that both composite were sensitive and gave negative impact on tensile properties. More ductile effect was found in the composites and its reverse effect on fracture, especially for TPEE composite. Generally, ductile material gives better performance against fracture but in this case it was reverse mostly because of weak bonding between matrix material and TPEE ( Dani et al., 2009). Chang et al. has compared results obtained from various material models with regards to fibre orientation prediction (Chang et al., 2018). Hashemi (2011) studied the effect of number of gates and temperature on tensile strength and strain rate. His work has been carried out using $10 \%$ and $30 \%$ glass filled PBT material. He observed that use of single gate resulted in better fibre orientation as compared to multiple gates. Gupta et al. studied the effect of thickness variation and injection speed on the fibre orientation in the flow front. He observed alignment of fibres in the direction of flow and fibres in the transverse direction to the flow near the skin and core area of the moulded part, respectively (Gupta and Wang, 1993). Marcus et al. studied the behaviour of glass filled material by varying strain rate. This work is pertaining to unfilled and glass fibre filled Polypropylene material. He reported increase in tensile strength by changing strain rate, particularly above 20 per second (Marcus et al., 2008). Peter et al. studied the importance of fibre orientation prediction through iARDRPR model. This work reported comparison of predicted and experimental fibre orientation for $30 \%$ glass filled PBT material. He found that iARD-RPR model is effective as far as accurate fibre orientation is concerned (Peter et al., 2014). Zheng et al. has developed computational model to co-relate shrinkage and fibre ordination results. The results demonstrate good correlation between predicted and experimental values (Zheng et al., 2014). Thomason studied the effect of fibre loading, fibre diameter, fibre length on the mechanical properties of thermoplastic materials. He found that fibre diameter and fibre loading have significant effect on mechanical properties of the moulded part. Autodesk Moldflow tool help feature mentions about use of FolgarTucker orientation equation standard model for fibre orientation calculations. Recent experiments however, indicate that the Folgar-Tucker model over-estimates the 
change rate of the orientation tensor in concentrated suspensions. RSC (Reduced Strain Closure) model is developed to get better idea about slow orientation dynamics. This model aims at reducing the growth rates of the eigenvalues of the orientation tensor by a scalar factor, while leaving the rotation rates of the eigenvectors unchanged. Moldflow rotational diffusion (MRD) model gives better fibre orientation prediction compared to RSC model so it is used in many simulation software's to predict fibre orientation in $3 \mathrm{D}$ model (Thomason, 2006 a; 2007 b; 2007 c; 2009 d).

In present work 50\% glass filled Polyamide (PA-66) material is considered for the warpage prediction using existing simulation and integrative simulation approach. An industrial component Pro-fan made of $50 \%$ glass filled is injection moulded using optimum processing conditions is considered for this study. An integrative simulation of this component has been carried out using Ultrasim ${ }^{\circledR}$ software for the actual optimum processing conditions. Same industrial component is also analysed using moldflow software as an existing simulation software available for injection moulded process. The warpage values at predefined locations predicted by integrative simulation and existing simulation approach are then compared with actual experimental values. The comparison shows that warpage results predicted by integrative simulation approach are closer to actual experimental results as compared to predicted values using existing moldflow software. Thus, integrative simulation approach can be effectively used for prediction of warpage in injection moulded parts made of thermoplastic material. The components details, material selection, 3D scanning of actual moulded part and methodology is covered in further discussion.

\section{MATERIALS AND METHOD}

Material Selection: As fibre orientation and moisture directly affects warpage and shrinkage in the injection moulded parts, therefore BASF's Ultramid®A3WG10 commonly called 50\% glass filled polyamide (PA66) material have been considered for this study. The rheological and mechanical properties for this material was developed at BASF Laboratories and is used for making a new material model. Warpage analysis was carried out by maintaining actual moulding process conditions through existing simulation approach and integrative simulation approach (detailed procedure explained in section 2.5) using Ultrasim $®$ based new material model.

Component Selection: For this study an industrial component called 'Pro-Fan' with circular geometry have been considered. The selected component has features such as flatness, curvature, circularity, ribs and constant wall thickness. This part was manufactured by "Max Enterprises" Plastic Processing industry situated at Pune, India. To have a clear picture of warpage with geometrical variation, the part with little complex geometry have been chosen for this work. Figure 1 shows CAD models of the Pro-Fan with overall dimensions and cross-sectional details.

Part Manufacturing (Injection moulding): The sample parts are manufactured using injection moulding process. Injection moulding machine with 150 tons locking tonnage is used for moulding of these parts. The optimum process parameters are given in Error! Reference source not found. . 

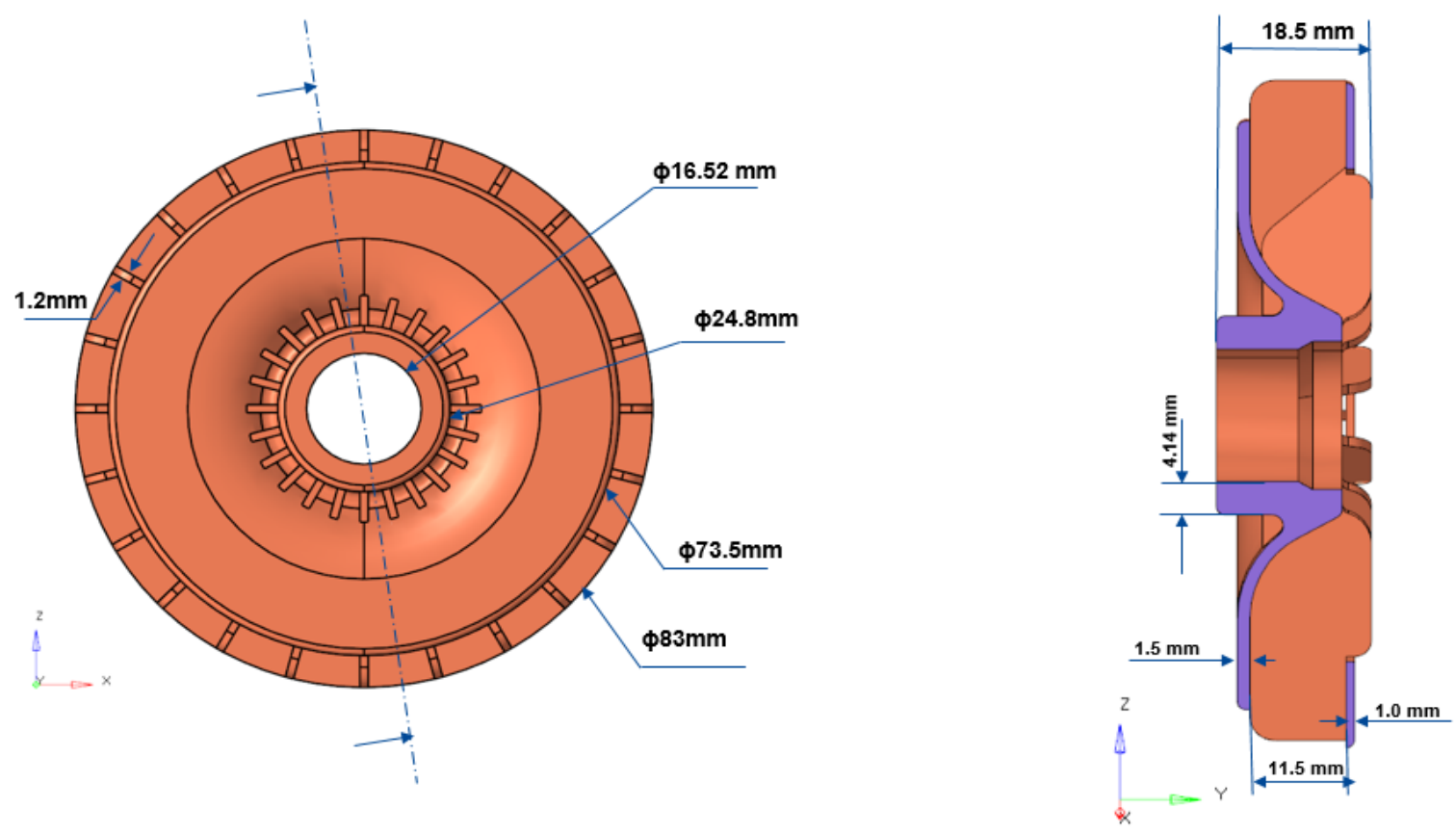

Figure 1 Three-dimensional CAD model of Pro-Fan

Table 1. Actual Process Parameters during injection moulding process

\begin{tabular}{ccc}
\hline Sr. No & Parameter & Magnitude \\
\hline 1 & Temperature, Zone1, ${ }^{\circ} \mathrm{C}$ & 310 \\
2 & Temperature, Zone2, ${ }^{\circ} \mathrm{C}$ & 295 \\
3 & Temperature, Zone3, ${ }^{\circ} \mathrm{C}$ & 280 \\
4 & Packing Pressure, bar & 95 \\
5 & Pre-heating time, Hours & 4 \\
6 & Time (Filling + & 11 \\
7 & Packing+ Holding), Sec & \\
& Cooling time, Sec & \\
& Machine Tonnage used, & \\
& Ton
\end{tabular}

Four edge gates are used for material filling in the cavity each of cross section $1 \mathrm{~mm} \times 1 \mathrm{~mm}$.

Figure 2 shows the actual injection moulded samples and corresponding gating system.

Process for Injection Moulding Simulations (Existing simulation methodology): Autodesk's Moldflow commercial injection moulding package is used to perform the injection moulding analysis. The analysis sequence is selected as fill + pack + warp as primary aim of this work is to predict warpage in the part.
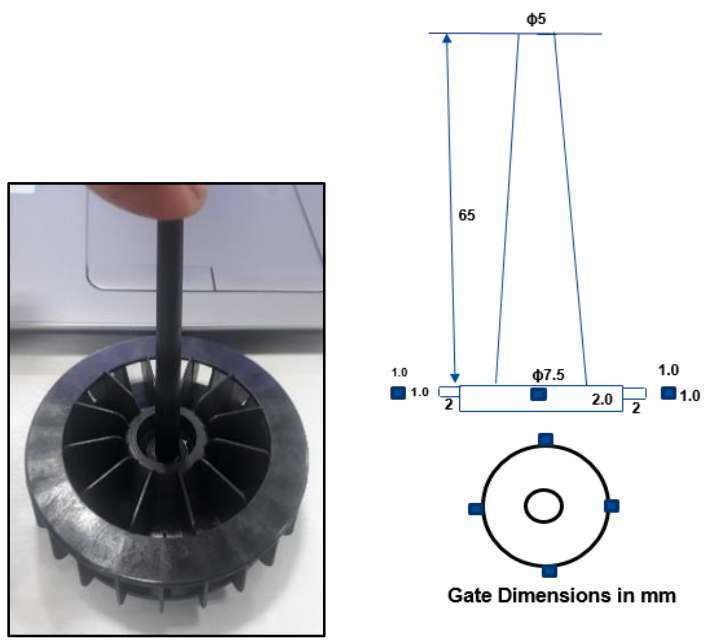

Figure 2. Actual moulded parts by injection moulding process and corresponding gate dimensions 
The surface mesh has been generated by using Altair's HyperMesh pre-processor software on the outer layer of the CAD model. An average element size is kept at $1.5 \mathrm{~mm}$ for outer skin layer. The internal volume mesh is generated with auto mesh generator with ten layers across the thickness have been defined in the Autodesk's Moldflow tool. The onedimensional beam elements are used for gating system in Autodesk's Moldflow software and appropriate cross sections are assigned as per actual inputs from injection moulding. Figure 3 shows the Autodesk's moldflow model and gating system. The injection location and process parameters such as. temperature, pressure, injection time, packing and cooling time are considered similar to actual injection moulding process parameters as mentioned in Error!

\section{Reference source not found.}

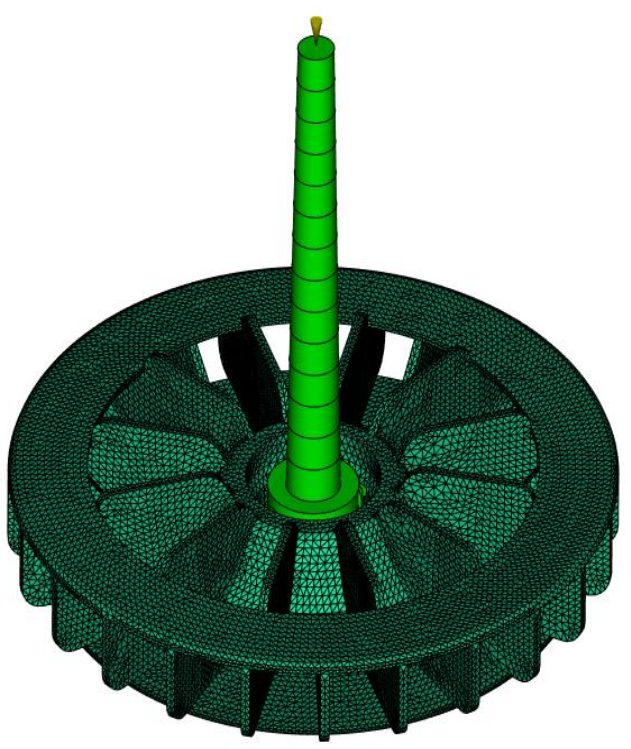

Figure 3. Three-dimensional Meshed model with gating system

The process simulation setup is then solved in moldflow solver. The results like fill pattern, temperature at flow front, melt temperature, shear rate, volumetric shrinkage and warpage are analysed with Autodesk's Moldflow viewer. The time required for material filling, packing, cooling etc., is verified with respect to actual moulding process. The displacements (Warpage + Shrinkage) are extracted at predefined locations as shown in Figure 7. The same pre-defined locations are used for integrative simulation analysis and actual experimental warpage measurements. Figure 4 shows a typical fibre orientation and warpage results obtained using existing moldflow simulation.

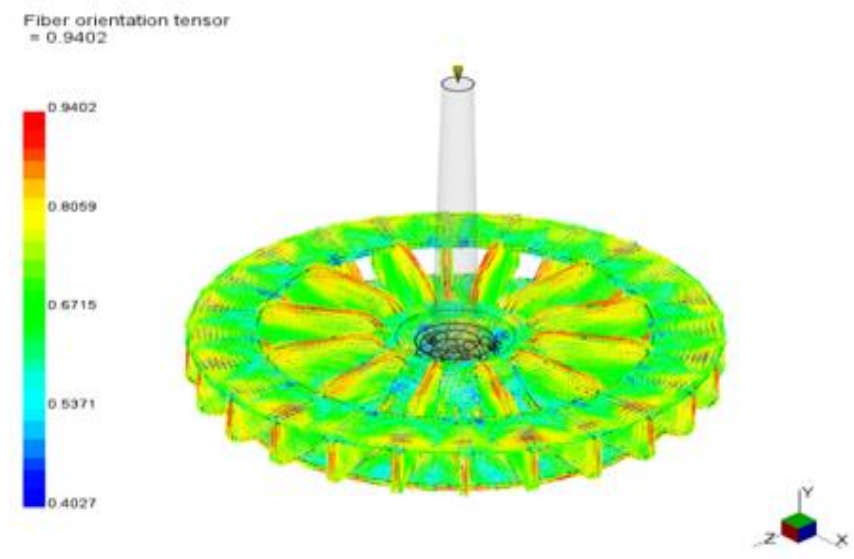

Deflection, all efrects: Deflection
Scaie Factor $=5.000$
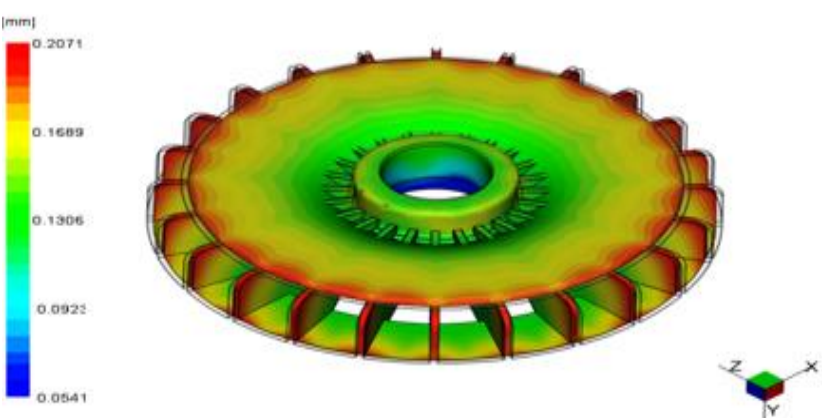

Figure 4. A typical process simulation fibre orientation and overall warpage plot

Process for Integrative Simulation Methodology: BASF developed Ultrasim $\AA$ software which is based on an integrative simulation method for the warpage analysis of injection moulded parts. It considers the output from the mould flow analysis as an input for material mapping. The output obtained from mould flow analysis are fibre orientation, pressure, temperature, volumetric shrinkage and density. Material mapping is done using BASF's Ultrasim $(\AA$ software. The mapped material model is separately used in Abaqus solver from Dassault Systems to solve finite element equation (Glaser, 2005 a; 2006 b; 2009 c; Kraft et. al., 2009; Wust et al., 2009). This new integrative simulation methodology is based on following points:

1. It considers fibre orientation in the material model as per material flow inside the cavity leading to more realistic stiffness of the material.

2. It considers visco-elastic and thermo-mechanical behaviour which are close to real scenario, while solving finite element equations. Commercial 
packages considers linear elastic behaviour with regards to plastic material.

3. It considers variable temperature, stress relaxation and transient cooling unlike traditional finite element solvers. The results such as warpage, temperature and stresses can be predicated precisely after ejection with transient cooling to room temperature.

4. The effect of mould constraints on shrinkage and warpage can be considered by adding special constraints in the simulation model.

For mapping process basic discretised finite element model has been used. The sample components are modelled with second order tetrahedron elements with average element size of $1.5 \mathrm{~mm}$. The output results from injection moulding simulation viz. fibre orientation, temperature, pressure, density, volumetric shrinkage and the temperature dependent material properties with corresponding rheological properties are used as input for the mapping process. The loading and boundary conditions are applied as per analysis requirement to solve the finite element matrix equation. Entire mapping process is done with the help of Ultrasim $®$ software to develop new mapped material model. Output file with new material model from integrative mapping procedure is solved in commercial finite element solver viz. Abaqus Solver. The flow chart of an integrative simulation is shown in

Figure 5. The time dependent transient step has been defined with first increment as filling condition, i.e. from melt temperature to ambient temperature $\left(23^{\circ} \mathrm{C}\right)$ at which complete solidification of melt occurs. The solver automatically takes in-between increments as per convergence requirement. The output solution files are then post processed with Altair HyperView. The displacement at pre-defined points on the part are as shown in Figure 7. Inspection, scanning methodology and results are explained in the next section.

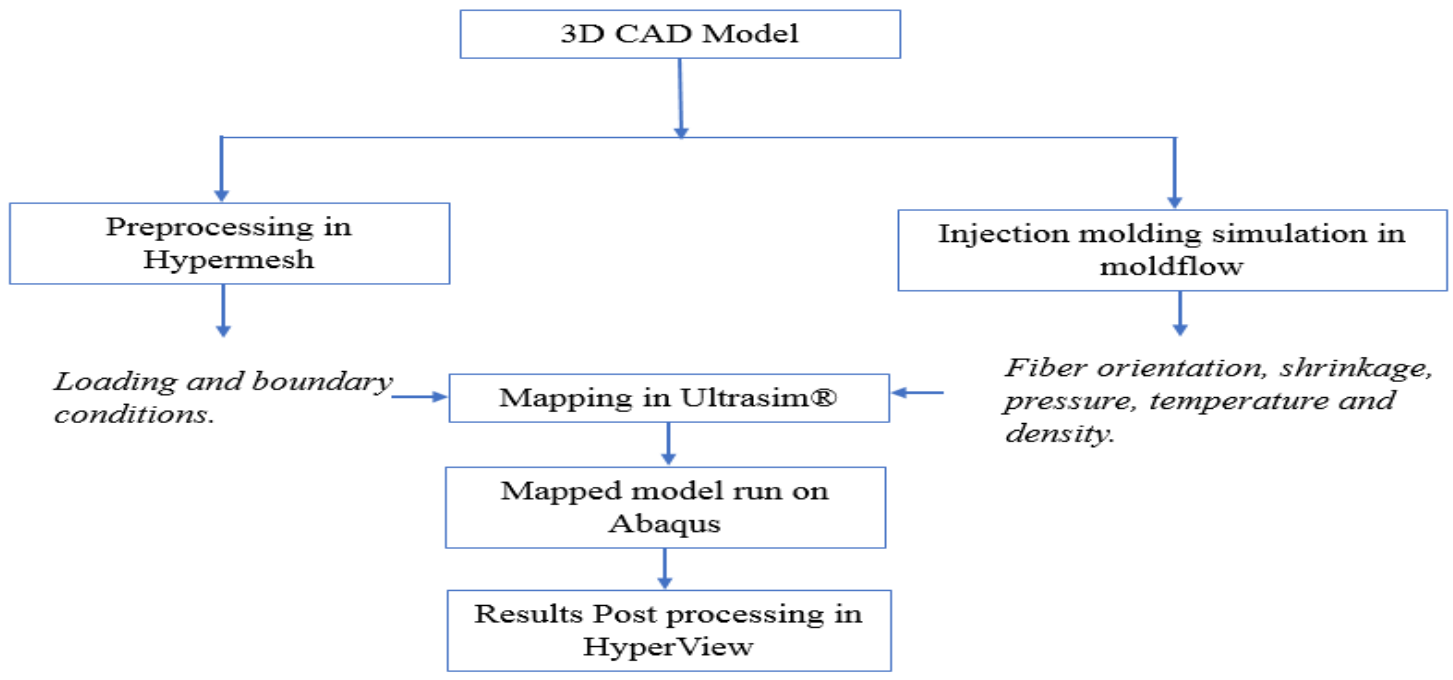

Figure 5. Workflow for integrative simulation

Three-Dimensional Scanning of actual moulded parts: After warpage analysis through simulation software, scanning of the actual moulded part is carried out at Solid Vision laboratory, Mumbai, using Einscan pro plus 3D Scanner and Geomagic Control X. This technology is used for the scanning of injection moulded parts and for generating three-dimensional data. This data can further be used for evaluating deviation with respect to CAD model. Figure 6 shows a plot of typical 3D scanning result.

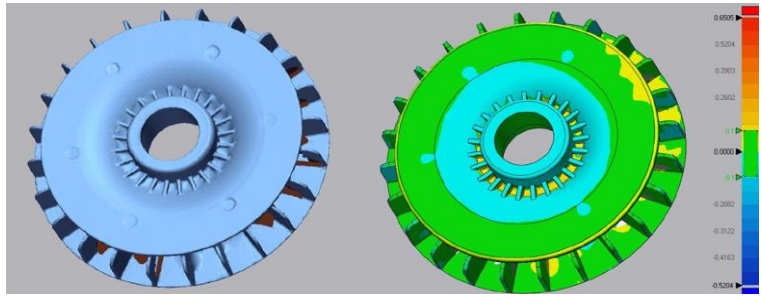

Figure 6. A typical 3-D scanning result 
The pre-defined locations with their coordinates are provided to laboratory as an input for deviation reference measurement points. Thus, the deviation in actual moulded part is recorded at pre-defined locations which have already been used for existing moldflow and integrative simulation method for warpage measurement.

\section{RESULT AND DISCUSSION}

For correlation study, the warpage results predicted by existing moldflow simulation method and new integrative simulation method Ultrasim $\AA$ are compared with actual experimental $3 \mathrm{D}$ scanning results at pre-defined reference locations on the actual part. Figure 7 shows the pre-defined reference locations on the CAD model which are considered for warpage measurement.
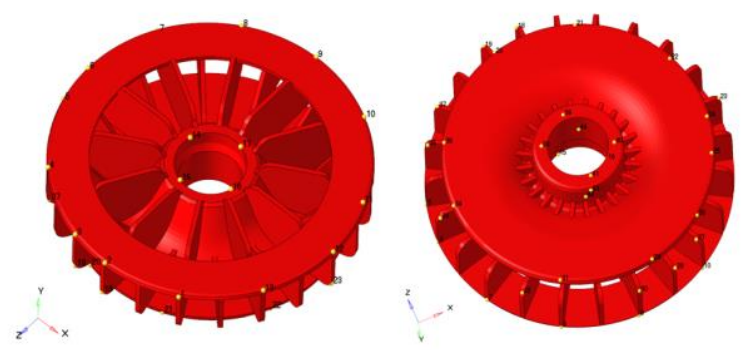

Figure 7. Reference points on CAD models

The reference points have been selected by considering maximum deflection locations from simulation results and visual inspection. The points are selected on alternate ribs from both sides. A typical total displacement/warpage plots of the existing moldflow simulation, integrative simulation method and $3 \mathrm{D}$ scanning mapped points results are shown in Figure 8. From the results it is observed that the pattern of overall displacement at reference locations is similar for existing simulation and integrative simulation approach however displacements predicted by integrative simulation at various predefined locations are closer to actual experimental values.

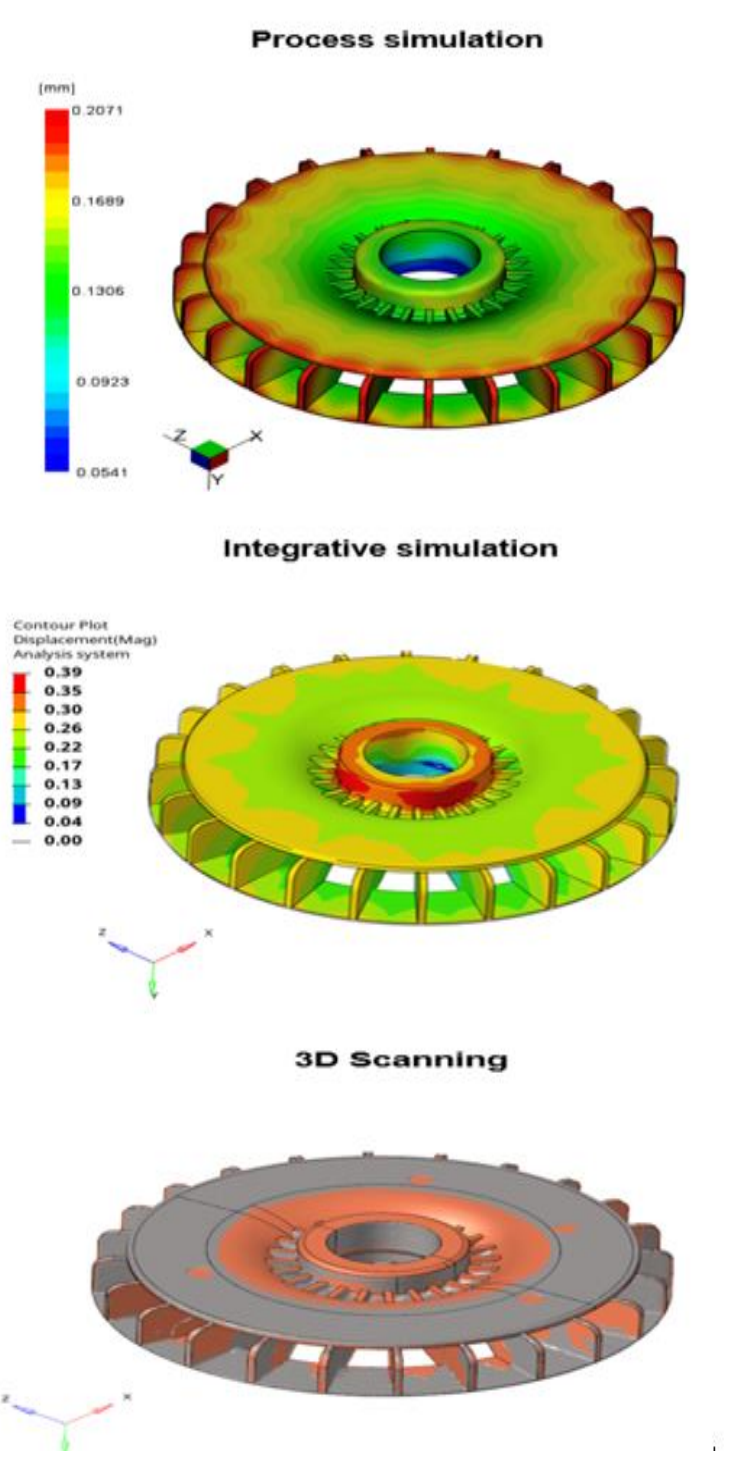

Figure 8. Warpage results comparison plot of existing process simulation, integrative simulation and $3 \mathrm{D}$ scanning

Figure 9 shows graphical representation of warpage at various reference locations obtained using all three methods. In the graph warpage values obtained by each method are plotted along $\mathrm{Y}$ axis and reference point location numbers are plotted along $\mathrm{X}$ - axis. 


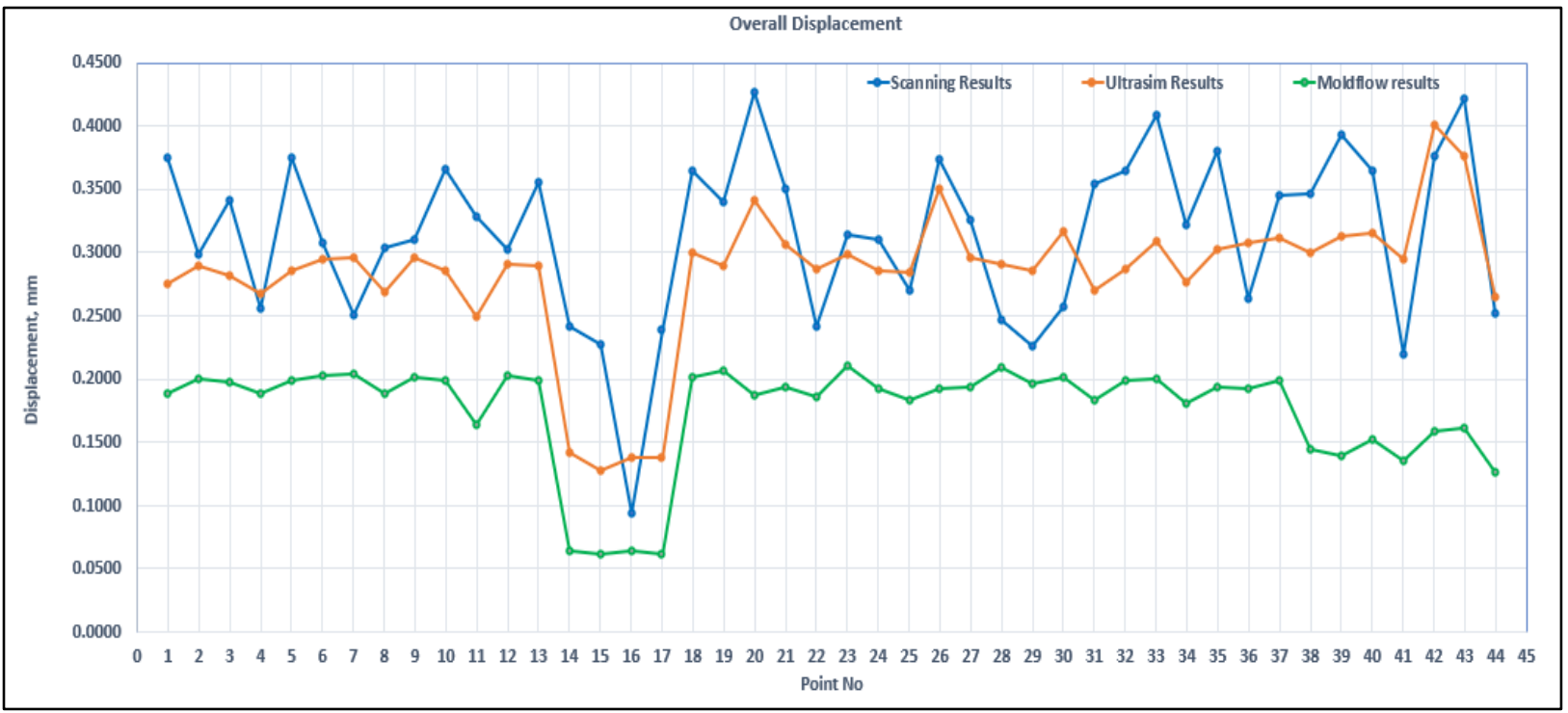

Figure 9. Variation in warpage at predefined reference locations for $3 \mathrm{D}$ scanning, integrative simulation and process simulation

From the graph as shown in Figure 9, it is clear that pattern of warpage values is not exactly same for both the simulation results at all reference locations. However, the integrative simulation results at most of the reference locations are closer to the actual $3 \mathrm{D}$ scanning results as compared to existing simulation results.

\section{CONCLUSION}

In this study the warpage analysis is carried out for $50 \%$ glass filled polyamide PA66 material using existing simulation method and new integrative simulation method. The results obtained from both the methods are compared with actual $3 \mathrm{D}$ scanning inspection results. The effect of the fibre orientation, moisture, volumetric shrinkage, temperature, density, pressure etc., are considered in non-linear and transient domain for integrative approach. From the analysis it is clear that integrative simulation method results are closer to the actual scanning results. Hence it is concluded that an integrative simulation approach gives more accurate warpage results as compared to existing traditional simulation method for glass filled polyamide PA66 material.

In the present work the warpage values predicted by new integrative simulation approach fairly agree with actual experimental warpage values for 50\% glass filled polyamide PA66 material. This work can be further extended for different loading of glass fibres in polyamide material.

\section{REFERENCES}

Akay, M \& Barkley, D 1991, 'Fiber orientation and mechanical behaviour in reinforced thermoplastic injection molding', Journal of Material Science, vol. 26, pp. 2731-2742.

BASF Press release, 2020, Thermo-mechanical-modeling, viewed 15th June 2020, <https://plasticsrubber.basf.com/en/PerformancePolymers/Thermomechanical-modeling.html>.

Divekar, M, Gaval, V, \& Wonisch, A 2020, 'Improvement of warpage prediction through integrative simulation approach for thermoplastic material', Journal of thermoplastic composite materials, vol. 1, pp. 1-18.

Fung, C 2004, 'Fiber orientation of fiber reinforced PBT composite in injection molding', Plastics Rubber and Composites, vol. 33, no. 4, pp. 170-176.

Glaser S, Wüst, A \& Jansen, J 2006, Crashbelastete Bauteile virtuell entwickeln, Technische Kunststoffe, Carl Hanser Verlag, Munchen.

Glaser, S \& Wüst, A 2005, Modellierung am Computer, Kunststoffe, Carl Hanser Verlag, Munchen. 
Glaser, S, Jakobi, R \& Kraft, W 2009, 'Simulation, Production, Testing, Complete Package for Plastic Component Development', ATZ worldwide, vol. 111, pp. 3641.

Glaser, S, Wonisch, A \& Daniel, F 2019, 'Thermomechanical simulation of glass-fiber-reinforced plastic components with Ultrasim $® '$, in International Congress for Plastics in Automobiles: Plastics in automotive Engineering, 3-4 April 2019, Europe, Mannheim, Germany.

Huan-Chang, T \& Rong-Yeu, C 2018, 'Comparison of recent fiber orientation models in injection molding simulation of fiber-reinforced composites', Journal of Thermoplastic Composite Material, vol. 16, pp. 456-463.

Huan-Chang, T, Rong-Yeu, C, \& Chia-Hsiang, H 2017 , 'Numerical prediction of fiber orientation and mechanical performance for short/long glass and carbon fiberreinforced composites', Composites Science and Technology, vol. 144, pp. 51-56.

Izadi, O \& Mosaddegh, P 2019, 'Experimental and simulation study on the warpage of polyamide 6 based on thermomechanical behavior of material using uniaxial tensile test', Amirkabir J. Mech. Eng., vol. 52, vol. 5, pp. 13 .

Jian,F, Du, J \& Yang, M 2015, 'Optimization of injection process parameters to reduce warpage in glass fiber reinforced polyamide molded parts', $5^{\text {th }}$ International conference on information engineering for mechanics and materials, 2015, Atlantis press.

Kaiser, J \& Stommel, M 2012, 'Micromechanical modelling and strength prediction of short fiber reinforced polymers', Journal of Polymer Engineering, vol. 32, pp. 43-52.

Kovacs, J \& Solymossy, B 2009, 'Effect of glass bead content and diameter on shrinkage and warpage of injection molded PA6', Polymer engineering and science, vol. 49, no. 11, pp. 2218-2224.

Thomason, J 2006, 'Structure-property relationships in glass-reinforced polyamide, part1-effect of fiber content', Polymer Composites, vol. 27, no. 5, pp. 552-562.

Thomason, J 2007, 'Structure-property relationships in glass-reinforced polyamide, part2-effect of average fiber diameter and diameter distribution', Polymer Composites vol. 28, no. 3, pp. 331-343.

Thomason, J 2007, 'Structure-property relationships in glass-reinforced polyamide, Part3- Effect of hydrolysis aging on the dimensional stability and performance of short glass-fiber-reinforced polyamide 66', Polymer Composites, vol. 28, no. 3, pp. 344-354.
Thomason, J 2009, 'The influence of fiber length, diameter and concentration on the impact performance of long glassfiber reinforced polyamide 66', Applied science and Manufacturing Part A, vol. 40, no. 2, pp. 1141-124.

Wüst A, Hensel, T \& Dirk, J 2009, 'Integrative Optimization of injection-molded plastic parts: 7th European LS-DYNA Conference, 14-15 May 2009, Salzburg, Austria.

Zheng, R, Mccaffrey, N \& Winch, K 2014, 'Predicting warpage of injection molded fiber-reinforced plastics', Journal of Thermoplastic Composite Material, vol. 9, pp. 90-106. 